九州大学学術情報リポジトリ

Kyushu University Institutional Repository

\title{
A Preliminary Study of Anchovy (Engraulis japonica) Larval Drift and Growth by Numerical Simulation
}

Kim, Dong-Sun

Research Center for Ocean Industrial Development (RCOID), Pukyong National University

Kang, Ik Joon

Faculty of Agriculture, Kyushu University

https://doi.org/10.5109/26159

出版情報: 九州大学大学院農学研究院紀要. 58 (1)，pp.37-49，2013-02. Faculty of Agriculture， Kyushu University

バージョン :

権利関係 : 


\title{
A Preliminary Study of Anchovy (Engraulis japonica) Larval Drift and Growth by Numerical Simulation
}

\author{
Dong-Sun KIM ${ }^{1}$ and Ik Joon KANG* \\ Faculty of Agriculture, Kyushu University, Fukuoka 812-8581, Japan \\ (Received October 31, 2012 and accepted November 8, 2012)
}

\begin{abstract}
To understand seasonal drifts and growth characteristics of anchovy (Engraulis japornicus) larvae in the South Sea of Korea, residual flows were estimated, and then two cases, without and with biological activity, were implemented into numerical simulations. Residual flows were closely related to local wind speeds and directions at surface or in shallow water. Residual flows appeared the strongest in the autumn and weakest in the winter. The patterns of residual flows offshore showed to be similar to that of the Tsushima Warm Currents. During the spring and summer, there was a tendency for larvae to be transferred westward when the southeasterly or southerly winds were dominant. Most larvae were drifted eastward via the currents and converged at the boundary between coastal water and offshore water. Summer had the highest biomass increase, affected by high temperature and high concentration of nutrients being transported from land due to high rainfall. On the other hand, winter had the lowest biomass increase due to low temperature. Spatially, the northern group showed much higher biomass increase than did the Jeju group due to the high concentration of nutrients distribution. The maximum biomass increase for larvae was 187 times after 30 days comparing to initial release, which is comparable to actual value. This study was performed as a preliminary experiment using numerical model to understand the movement and growth of anchovy larvae. The effectiveness of numerical model adaption was well verified by the results. Understanding the movement and growth of larvae for a target species is very important since it is closely related to the productivity of adult. In this respect, this experiment will be contributed as one of tools to study time and spatial movement and growth of larvae for a target species.
\end{abstract}

Key words: anchovy, biomass, Engraulis japornicus, larvae, numerical simulation, residual flow

\section{INTRODUCTION}

Pacific anchovies (Engraulis japonica) are distributed on the coasts of Korea, Japan, China, Taiwan and Sakhalin, Russia. The main anchovy fishing grounds in Korea are near the coast of the South Sea of Korea. Yearly production is almost consistent, without much fluctuation (NFRDI, 2010a and 2010b).

There have been many studies on the biological characteristics of anchovy over the last several decades in Korea: distribution of larvae (Kim, 1983), spawning (Kim and Choi, 1988; Kim and Kang, 1992), growth (Cha, 1990), feeding habits (Park and Cha, 1995), formation of fishing grounds (Kim et al., 1988; Lee and Kim, 1998; Seo and Kim, 1999), distribution of anchovy (Whang and Kim, 1977; Kim et al., 1991a; Kim and Lo, 2001, Park and Yoon, 1996), etc. Studies on physical properties that affect the movement and distribution of larvae will be very useful for predicting and estimating resources for target species. However, previous studies were very limited and mainly focused on physical factors such as currents and water masses.

The west of the study area is very shallow and connected to the Yellow Sea through the Jeju Strait, and has strong tidal currents. The topography of the bottom layer is almost parallel with the coastal line and is up to $50 \mathrm{~m}$ in depth. On the contrary, the east of the study area is

\footnotetext{
${ }^{1}$ Research Center for Ocean Industrial Development (RCOID), Pukyong National University, Busan 608-737, Republic of Korea

* Corresponding author (E-mail: kangnew@agr.kyushu-u.ac.jp)
}

relatively deep and connected to the East Sea of Korea/ Japan Sea through the Korean Strait, and has weak tidal currents. Depth increases rapidly to $100 \mathrm{~m}$ off the coast of northern Jeju Do and northern Tsushima. A submarine valley deeper than $200 \mathrm{~m}$ developed at a west channel between Pusan and Tsushima and runs parallel with the Korean Strait (Fig. 1).

There are various types of water masses in the South Sea of Korea: Tsushima Warm Currents Water, South Sea Coastal Water, Yellow Sea Bottom Cold Water, Yangtze River Low Salinity Water and Korea Strait Bottom Cold Water, etc. (Kim et al., 1991b; Chang et al., 1995; Cho and Kim, 1995). Therefore, the South Sea of Korea is affected and mixed by several different waters of various origins throughout the year, forming frontal boundaries (Gong, 1971; Huh, 1974; Noh, 1990; Bae and Kim, 2011).

Thus, the ecosystem in the South Sea of Korea is very complicated and differs from the two other neighboring seas, the Yellow Sea and the East Sea of Korea/Japan Sea) (Kim and Kang, 2000). In particular, the diversity in the South Sea is noteworthy, consisting of greater than 70\% of fish species appearing near the coasts of Korea (Kim and Ko, 2003; Lee, 2004). Since the South Sea of Korea has a very complicated coastal line, consists of many islands, and is affected by Tsushima Warm Currents, it plays a very important role for domiciling fish, as well as migrating fish, for spawning or growing grounds (NFRDI, 1998b).

To predict the drift of larvae in coastal zones, sea circulation must be precisely and quantitatively reproduced in the model domain. Because all boundaries of the study area are open except the northern boundary, 
water exchange between the inside and the outside of the model domain is very active. It is possible that the flow pattern at the shallow South Sea of Korea is produced by mean flows influenced by wind, irregular bottom topography, and tidal currents. The various types of water masses, however, play primarily important roles in sea circulation and water exchange between the inside and the outside of the model domain in the South Sea of Korea (Chang et al., 1995). If an open boundary exists, it is necessary to reproduce sea circulation by incoming and outgoing flows with time variation through the open boundary. Previous studies showed that changes in current in the South Sea of Korea were remarkable in time and space (Chang et al., 1995; Suk et al., 1996).

Due to the high mortality of the larvae stage, survival rate is closely related with variation in resources. In addition, environmental factors such as spawning and growing grounds largely affect the survival rate of larvae. Because larvae are not capable of freely swimming and are mostly non-motile, they are not able to find optimal areas for habitats. Rather, their habitats are passively decided by physical environments. Therefore, density, currents, and winds are important factors for larvae in deciding their movement (Heath, 1989; Nakata, 1991). Further, these factors are primarily related to the survival rate of larvae and ultimately rule the production of marine sources. Because of the high mortality rate of larvae during their early stages, it is necessary to study the mechanisms of movement in order to investigate the state of the sea on spawning grounds and the spatial distribution of larvae after several days of spawning.

To study anchovy larvae movement and growth in the South Sea of Korea, the main anchovy fishing grounds, seasonal variations of residual flows were estimated by a numerical hydrodynamic model. Then, a coupled hydrodynamic model with the ecosystem model was applied to produce the distribution of movement and growth of larvae in two cases, without and with feeding.

\section{MATERIALS AND METHODS}

\section{Residual Flow Estimate}

To predict the advection and dispersion of material in the South Sea of Korea, circulation was produced using a three-dimensional ocean circulation model, the Princeton Ocean Model (POM) (Blumberg and Mellor, 1987). Residual flows produced by several physical factors such as water temperature, salinity, wind, currents and tidal currents are main forces affecting circulation in the coastal zone. Water exchange between the inside and the outside of the model domain was brisk because all boundaries were open except at the coast (Fig. 1).

The model domain was set up between Jindo and Jeju Do, Korea, as the western boundary, between the east of Jeju Do and Kyushu, Japan, as the southern boundary, and between Ulsan, Korea and Kyushu, Japan, as the eastern boundary. The northern boundary was closed by land, as mentioned earlier (Fig. 1). The total size of the horizontal domain was $288 \mathrm{~km}$ in longitude by $241 \mathrm{~km}$ in latitude. In order to express the very complicated coastal area and the various depths, the grid size was set up as $1 \mathrm{~km}$. Vertical direction was divided into seven layers using $\sigma$-coordinates from the surface to the bottom. Nautical charts 219, 229 and 836 were used for bottom depths, as published by the Korea Hydrographic Oceanographic Administration. Time interval was set up as 5 seconds in considering CFL (Courant-FriedrichsLewy) conditions. Total simulation period was 45 days.

Tidal currents were calculated based on harmonic constants (KORDI, 1996), the four principal tidal components $\left(\mathrm{M}_{2}, \mathrm{~S}_{2}, \mathrm{~K}_{1}\right.$, and $\left.\mathrm{O}_{1}\right)$. It is difficult to apply the effects of wind on the surface of the ocean due to the frequent

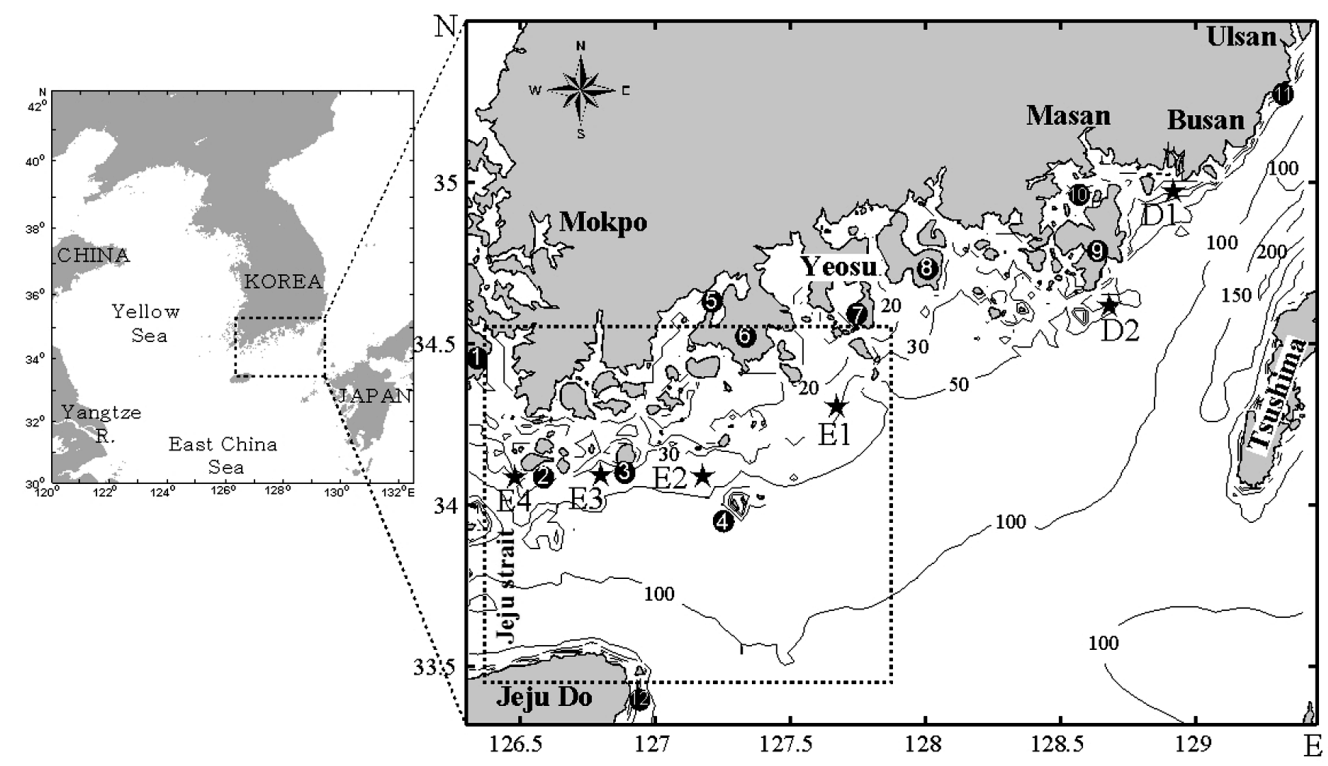

Fig. 1. Study area and bottom topography in the South Sea of Korea. Contour numbers in depth (m) (Black circles: 1. Jindo, 2. Bogildo, 3. Cheongsando, 4. Geomundo, 5. Deuckryang Bay, 6. Goheung, 7. Dolsando, 8. Namhaedo, 9. Geojedo, 10. Jinhae Bay, 11. Gijang, 12. Seongsan; Star marks: current meter stations) 


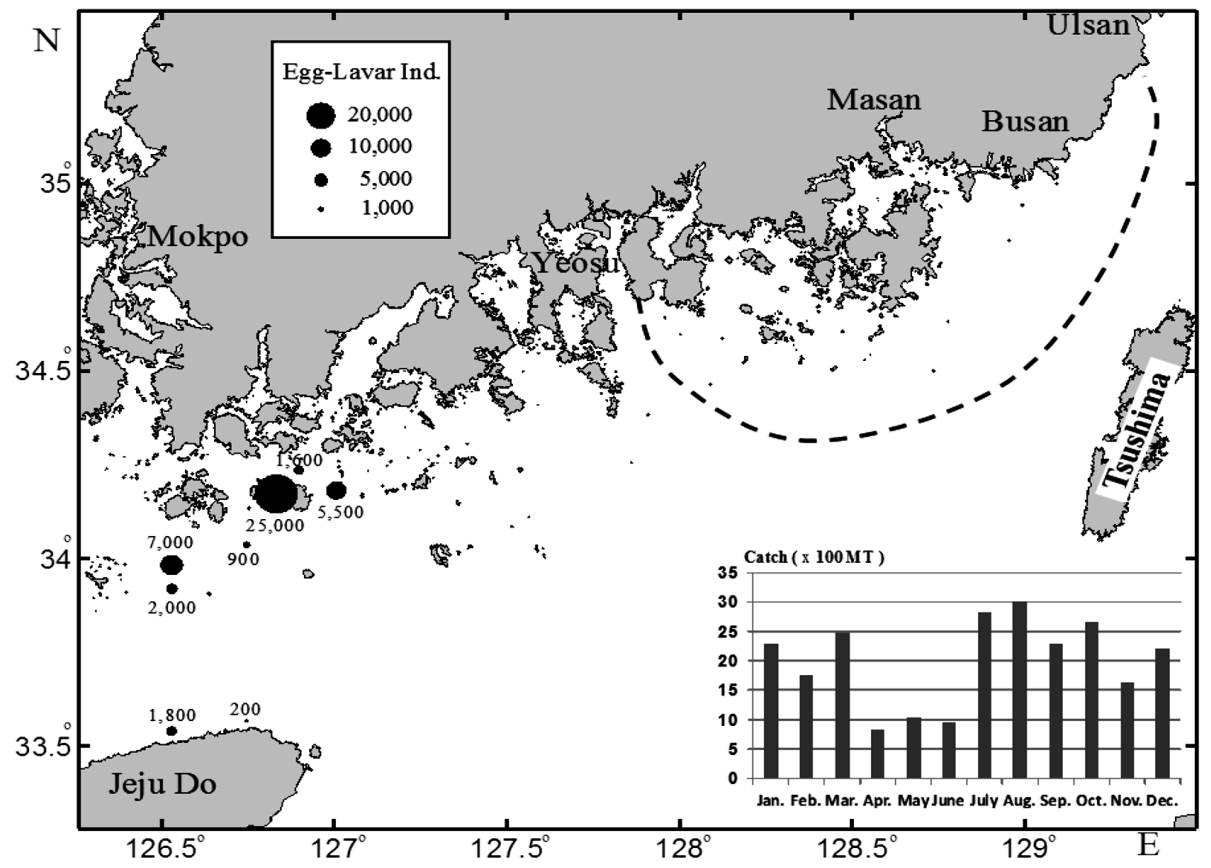

Fig. 2. The initial distribution of anchovy larvae and main fishing ground of anchovy (inside of dot line: main fishing ground) and catch (table in figure).

temporal-spatial changes in wind direction and speed. Therefore, wind speeds for spring, summer, and fall were adapted uniformly to $8 \mathrm{~m} / \mathrm{sec}$ without taking into consideration seasonal variation, and that for winter was estimated to be $10 \mathrm{~m} / \mathrm{sec}$ based on annual mean speeds (KMA, 2012). Since changes in wind direction largely impact circulation in coastal zones, seasonal mean directions were applied (spring: southeasterly; summer: southerly; fall: northwesterly; winter: northwesterly).

The initial spatial distribution of water temperature and salinity was set using mean values from five years (2003 2007) published by the National Fisheries Research and Development Institute. Tsushima Warm Currents are separated into two branches after passing Jeju Do. West side currents were named the "Jeju Warm Currents" and flowed into the model domain through the western boundary. The remainder kept its name as the Tsushima Warm Currents and joined the model domain through the southern boundary. Jeju Warm Currents from the western boundary and Tsushima Warm Currents from the southern boundary were considered the total incoming flow into the model domain. There was no incoming flow through the eastern boundary. The mean transport from the western boundary was known as 0.59Sv (Teague et al., 2002). Since the transport from the southern boundary was unknown, it was indirectly estimated by submitting the transport of the western boundary (0.59Sv) from the mean transport, 3.44Sv, of the Tsushima Warm Currents (spring: 2.7Sv, summer: 3.0Sv, autumn: $3.5 \mathrm{~Sv}$, winter: $2.2 \mathrm{~Sv}$ ) resulting in $2.85 \mathrm{~Sv}$ from the southern boundary.

\section{Low Tropic Ecosystem Model}

For this study, a coupled hydrodynamic model using the Princeton Ocean Model with the ecosystem model,
COHERENS (Luyten et al., 1999), was applied to produce the temporal-spatial distribution of ecosystem factors. A low tropic ecosystem model was implemented after 15 days of hydrodynamic model simulation in order to consider the spin-up time from the rest. The initial flux constituents of the ecosystem model were nutrients (nitrate and ammonia), detritus, and biomass of phytoplankton and zooplankton.

All ecosystem data obtained from the National Fisheries Research and Development Institute were interpolated or extrapolated for the spatial distribution of each grid. Due to the lack of detritus data, suspended material data were used to indirectly estimate the detritus by assuming that detritus is $10 \%$ in suspended material (Eppley et al., 1977). Also, due to the lack of data on phytoplankton biomass, chlorophyll-a data were used to infer phytoplankton carbon by multiplying by fifty (Cho and Azam, 1990).

\section{Anchovy Larvae Model}

Generally, it takes an average of 30 days after spawning for anchovies to become able to swim freely and to reach $2 \mathrm{~cm}$ in body length (NFRDI, 2010b). Therefore, larvae movement was traced for 30 days until they had free swimming ability. The initial value used was based on the distribution of larvae (NFRDI, 2004) surveyed in July of 2001 (Fig. 2). Two cases of anchovy larvae model were implemented: 1) without biological activity, and 2) with biological activity.

\section{Without Biological Activity (Case 1)}

To test temporal and spatial variation of anchovy larvae advection and dispersion with assumption of no biological activity, the particle tracking technique was adapted using the Lagrangian method. The advection and 


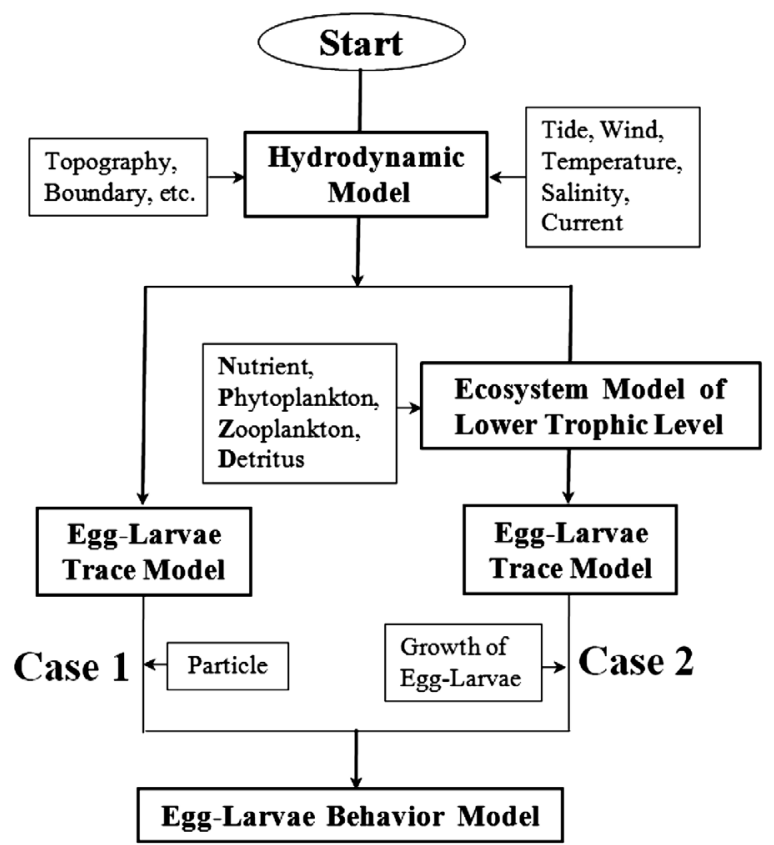

Fig. 3. The schematic flow chart of drift and growth for anchovy larvae.

dispersion of particles can be estimated by applying circulation in conjunction with particle tracking techniques (Siegel et al., 2003) (Fig. 3). Generally, material dispersion equation can be solved by numerical approach having approximate value. Another method is applying the Monte Carlo simulation with the assumption of the particle's random walk. The Monte Carlo method was used for this study due to the benefits of reproducing the particle and easy analysis of results.

$$
\mathrm{X}_{\mathrm{n}+1}=\mathrm{X}_{\mathrm{n}}+U \times \Delta \mathrm{t}+\mathrm{R}
$$

where $U$ : current velocity, $R$ (random walk): $\gamma \sqrt{6 K_{x} \Delta t}$, $\gamma$ : uniform random number (average $=0$, standard deviation $=1$ ), and $K_{x}$ : horizontal vorticity diffusion coefficient.

\section{With Biological Activity (Case 2)}

By simulating the low tropic ecosystem model, a spatial distribution of anchovy's main food, zooplankton, was produced. The advection and dispersion of anchovy larvae were simulated in the initial spawning area when affected by physical conditions and ecosystem (Fig. 3). It was assumed that the increase in biomass of anchovy larvae was mainly due to zooplankton consumption, while biomass decrease was due to natural mortality and predation.

$$
\beta(\mathrm{Z})=G N_{\mathrm{r}}(1-e)-d \mathrm{~N}
$$

where $G$ is predation pressure of phytoplankton, $N$ is biomass and $d$ is mortality rate (0.05/day, Lo et al., 1989). To estimate the uptake rate of zooplankton from phytoplankton, the empirical equation of Ivlev (1966) was adapted.

$$
\text { Grazing }=R_{\max }\left(1-e^{(-7 \text { phy })}\right), R_{\max }=0.024 e^{(0.12 t)}
$$

Where $R_{\max }$ is maximum feeding rate by temperature (Petipa, 1966), phy is the density of phytoplankton (mg $\mathrm{C} / \mathrm{L})$ and $t$ is temperature $\left({ }^{\circ} \mathrm{C}\right)$.

\section{RESULTS}

\section{Seasonal Variations of Residual Flow}

Analyzed model results of four main tidal constituents were compared with observed data for model verification at 6 stations, D1, D2, E1, E2, E3, and E4 (Table 1). Even though the major axes of the largest constituents, M2, were slightly underestimated than observed values except station E2, the ratio of observation vs. model results range was relatively narrow, showing 76.4-121.4\%. The maximum phase difference in major axes between observation and model results for $\mathrm{M}_{2}$ constituents was $19.9^{\circ}$ except at station E2. Generally, the agreement between observation and model results were good providing confidence for the hydrodynamic model adapted.

Fig. 4 shows the seasonal variations of residual flow in three layers of surface, middle, and bottom. Typically, flows seem to be affected by wind near the coast and by Tsushima Warm Currents at offshore without regarding seasons. In the spring, all three layers seem to have similar patterns showing relatively strong northeastward currents of $20 \mathrm{~cm} / \mathrm{sec}$ at offshore and southeastward currents of $30 \mathrm{~cm} / \mathrm{sec}$ near the Jeju submarine valley, north of Jeju Do, due to the influence of density difference and Tsushima Warm Currents (Kim et al., 1991a; Lie and Cho, 1997). Unlike autumn and winter, during spring and summer northeastward currents along the coast prevailed at the surface. In the summer, after passing Jeju Strait, currents separated two branches before Tsushima, one moving to the northeast along the coast, the other eastward, joining the Tsushima Warm Currents. Relatively strong eastward and northeastward currents were characteristic through the layers over the domain. Specially, currents at offshore were much stronger than that of spring showing $30 \mathrm{~cm} / \mathrm{sec}$. It is generally believed that inshore currents are influenced by southerly winds, while offshore currents are largely controlled by Tsushima Warm Currents. In the autumn, the residual flow at the surface southwestward prevailed near the coast. On the other hand, they were remarkably southeastward in the Jeju Strait. This infers that strong northwesterly winds affect the surface of the ocean during autumn. In the meantime, residual flows in the middle and lower layers showed clear eastward at Jeju Strait and northeastward near the eastern area of the South Sea of Korea. Residual flows at the surface of inshore were mainly affected by wind, but they were, however, largely ruled by currents below the middle layers of offshore areas. In the winter, the residual flows at surface showed briefly southward over the domain. They prevailed northward below the middle layer at inshore and northeastward through the layer at offshore.

In conclusion, residual flows were inferred to be generated by several forces, winds, currents and tidal current. They were largely influenced by wind through the surface layer of inshore regions and by currents below 
Table 1. The comparison between observed and model results for four-main tidal constituents

\begin{tabular}{|c|c|c|c|c|c|c|c|c|c|}
\hline \multirow{2}{*}{ St. } & \multirow{2}{*}{ Const. } & \multicolumn{3}{|c|}{ Major Axis (cm) } & \multicolumn{3}{|c|}{ Minor Axis $(\mathrm{cm})$} & \multicolumn{2}{|c|}{ Phase (degree) } \\
\hline & & Observed & Model & Mo./Ob. (\%) & Observed & Model & Mo./Ob. (\%) & Observed & Model \\
\hline \multirow{4}{*}{ D1 } & $\mathrm{M}_{2}$ & 25.38 & 22.88 & 90.10 & 0.35 & 3.63 & 1037.10 & 35.02 & 15.18 \\
\hline & $\mathrm{S}_{2}$ & 9.79 & 13.17 & 134.50 & 0.27 & 1.24 & 459.20 & 35.09 & 20.80 \\
\hline & $\mathrm{K}_{1}$ & 13.33 & 17.82 & 133.60 & 0.90 & 2.91 & 323.30 & 36.84 & 73.05 \\
\hline & $\mathrm{O}_{1}$ & 9.72 & 12.92 & 132.90 & 0.50 & 1.15 & 230.00 & 37.56 & 46.16 \\
\hline \multirow{4}{*}{ D2 } & $\mathrm{M}_{2}$ & 30.20 & 23.46 & 77.70 & 1.88 & 1.26 & 67.00 & 16.09 & 25.25 \\
\hline & $\mathrm{S}_{2}$ & 9.58 & 13.59 & 141.80 & 2.37 & 1.12 & 47.30 & 16.45 & 25.18 \\
\hline & $\mathrm{K}_{1}$ & 23.73 & 14.70 & 61.90 & 1.62 & 0.47 & 29.00 & 27.73 & 41.23 \\
\hline & $\mathrm{O}_{1}$ & 17.07 & 14.99 & 87.80 & 1.45 & 1.37 & 94.50 & 31.96 & 47.70 \\
\hline \multirow{4}{*}{$\mathrm{E} 1$} & $\mathrm{M}_{2}$ & 26.17 & 20.02 & 76.40 & 4.00 & 5.43 & 135.80 & 173.42 & 164.38 \\
\hline & $\mathrm{S}_{2}$ & 9.34 & 13.37 & 143.10 & 1.81 & 3.21 & 177.40 & 168.45 & 161.10 \\
\hline & $\mathrm{K}_{1}$ & 16.45 & 7.82 & 47.50 & 3.41 & 4.69 & 137.50 & 12.28 & 152.57 \\
\hline & $\mathrm{O}_{1}$ & 11.26 & 10.36 & 92.00 & 2.97 & 5.87 & 197.60 & 1.52 & 155.58 \\
\hline \multirow{4}{*}{ E2 } & $\mathrm{M}_{2}$ & 21.04 & 25.54 & 121.40 & 11.27 & 5.80 & 51.50 & 143.23 & 10.02 \\
\hline & $\mathrm{S}_{2}$ & 9.84 & 16.16 & 164.20 & 7.70 & 2.86 & 37.40 & 160.15 & 11.69 \\
\hline & $\mathrm{K}_{1}$ & 5.36 & 14.88 & 277.60 & 3.17 & 6.59 & 207.90 & 42.47 & 147.91 \\
\hline & $\mathrm{O}_{1}$ & 5.60 & 12.65 & 225.80 & 3.84 & 2.24 & 58.30 & 28.67 & 148.16 \\
\hline \multirow{4}{*}{ E3 } & $\mathrm{M}_{2}$ & 34.18 & 33.16 & 97.00 & 18.25 & 5.10 & 27.90 & 163.74 & 164.16 \\
\hline & $\mathrm{S}_{2}$ & 17.00 & 20.97 & 123.30 & 9.57 & 2.68 & 27.80 & 169.81 & 163.78 \\
\hline & $\mathrm{K}_{1}$ & 9.18 & 10.61 & 115.60 & 2.77 & 4.52 & 163.20 & 21.12 & 109.33 \\
\hline & $\mathrm{O}_{1}$ & 8.96 & 5.53 & 61.70 & 4.08 & 1.66 & 40.70 & 20.98 & 113.47 \\
\hline \multirow{4}{*}{ E4 } & $\mathrm{M}_{2}$ & 47.05 & 42.54 & 90.40 & 7.71 & 6.99 & 90.70 & 150.42 & 130.84 \\
\hline & $\mathrm{S}_{2}$ & 25.71 & 28.27 & 109.90 & 2.39 & 4.76 & 199.10 & 151.90 & 130.62 \\
\hline & $\mathrm{K}_{1}$ & 9.65 & 6.36 & 65.90 & 1.06 & 0.91 & 85.80 & 176.71 & 104.89 \\
\hline & $\mathrm{O}_{1}$ & 10.47 & 2.88 & 27.50 & 2.30 & 0.56 & 24.30 & 175.52 & 103.75 \\
\hline
\end{tabular}

the middle layer at offshore. Eastward residual flow altered their direction to the northeast and flowed out of the eastern boundary via the channel between the Korean peninsula and Tsushima. Generally, estimated residual flow at offshore showed much similar flow pattern to the Tsushima Warm Currents.

\section{Drift and Growth of Anchovy Larvae}

Using data averaged over several years on anchovy larvae, time and spatial movements by residual flows and biomass change by preying zooplankton of two scenarios, without biological activity and with biological activity, were simulated. In order to maintain a sufficient number of larvae in the model domain, larvae were released every hour for a tidal cycle. The total number of larvae was about 44,000 individuals per release at eight sites in study area. The highest was 25,000 near Cheongsando (Fig. 2).

\section{Anchovy Larval Drift (Without Biological Activity)}

Since these experiments were focused on advection and dispersion by residual flows, the results are described time and spatial density change (number $/ \mathrm{m}^{3}$ ) of individuals (Fig. 5). For the convenience of description in figures, results were divided into two groups, northern and Jeju.
In the spring, some larvae in the northern group were transported out of the western boundary after 10 days by westward residual flows. The center with greatest density still remained near the initially released sites between Cheongsando and Bogildo. The Jeju group began to disperse and was transported southeastward. After 20 days, the high density of center became weaker by all direction dispersion. In the meantime, the Jeju group was transported eastward by the residual flows and aggregated at the east coast of Jeju Do. After 30 days, the northern group was moved further southward and met the Jeju group while density became weaker by dispersion. The center with high density of distribution of the Jeju group was drifted southeastward from the initially released area (Fig. 2). Generally, the westward movement of larvae seemed to be largely affected by southeasterly winds. Therefore, their eastward movement was limited and stagnated near the initial place.

In the summer, after 10 days, the individuals rapidly spread in all directions, and some were transported out of western boundary by the westward residual flows. Some individuals drifted to the coast and the mouth of Deuckrang Bay. After 20 days, some of individuals were drifted eastward to offshore regions of Goheung. Due to the relatively high dispersion compared to spring, the 

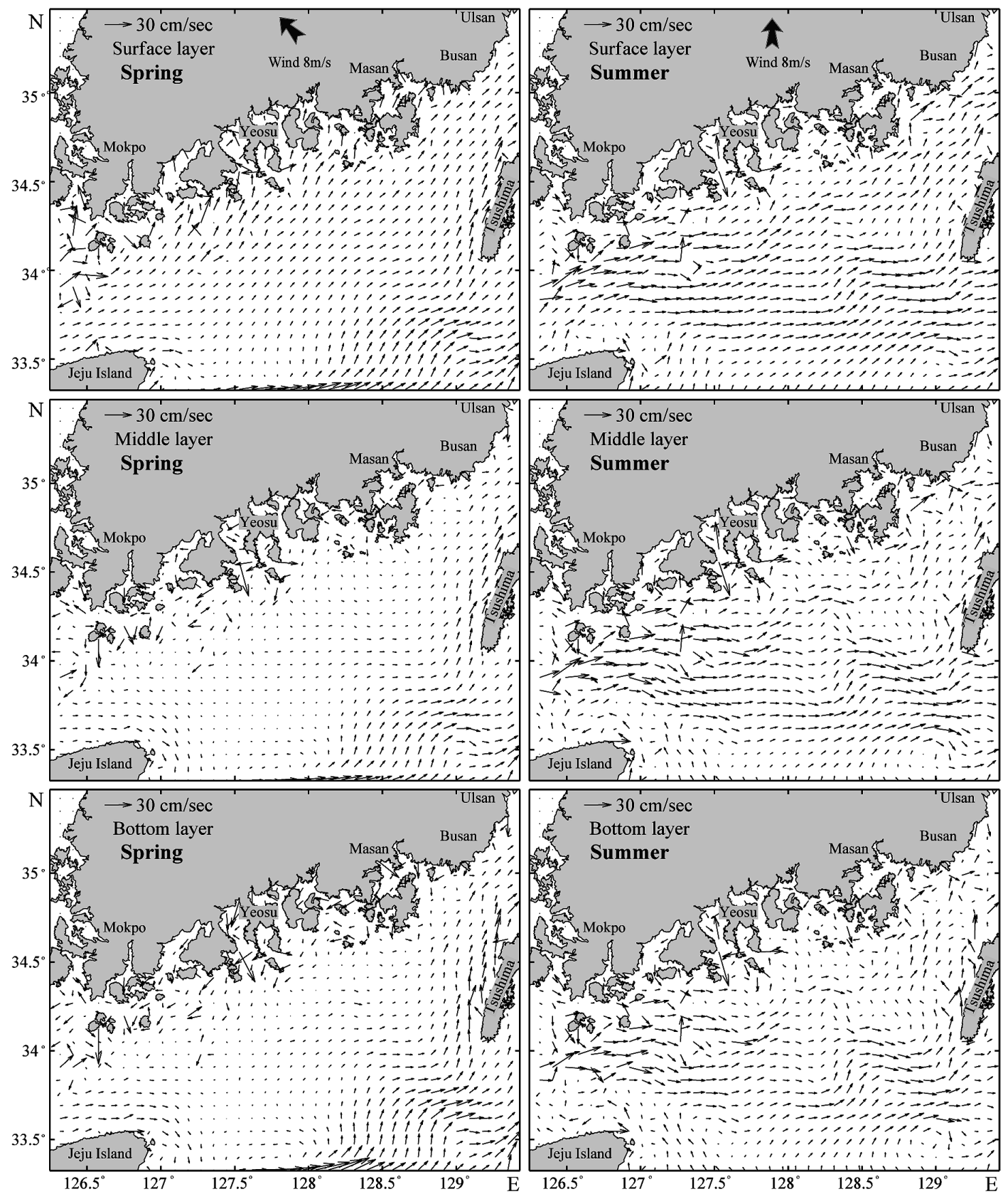

Fig. 4. Seasonal residual flows in the South Sea of Korea.

northern group joined the Jeju group 10 days earlier than in the spring. Generally, temporal and spatial dispersion during the summer became faster and wider rather than in the spring.

In the autumn, after 10 days, the northern group near Cheongsando began to move slowly northeastward and pushed into the Deuckrang Bay by residual flows, while some of them at offshore areas were dispersed southeastward. Most of the Jeju group left from the coast of Jeju Do, dispersing northeastward. After 20 days, the northern group dispersed rapidly eastward, passing offshore from Dolsando. The entire Jeju group left the coast of Jeju Do, dispersing eastward rapidly. After 30 days, two groups congregated near the front between coastal waters and Tsushima Warm Currents and dispersed further eastward by the residual flows. Unlike in the spring and summer, dispersion to the western boundary wasn't found during the autumn.

In the winter, after 10 days, the northern group moved inshore to the south of Bogildo and Deuckrang Bay by inshore residual flows, and some were transported to the coast of Goheong. After 20 days, the northern group drifted southeastward and the Jeju group was transported to the north while leaving the coast of Jeju Do. After 30 days, the northern group was dispersed further eastward and the Jeju group was dispersed eastward by residual flows. Even though the movement pattern seems a lot similar to that of autumn, the spatial dispersion is much smaller in the winter.

Locations of high distribution for larvae were altered seasonally by largely residual flows. In the spring, it transferred to the south of Bogildo-Cheongsando through 

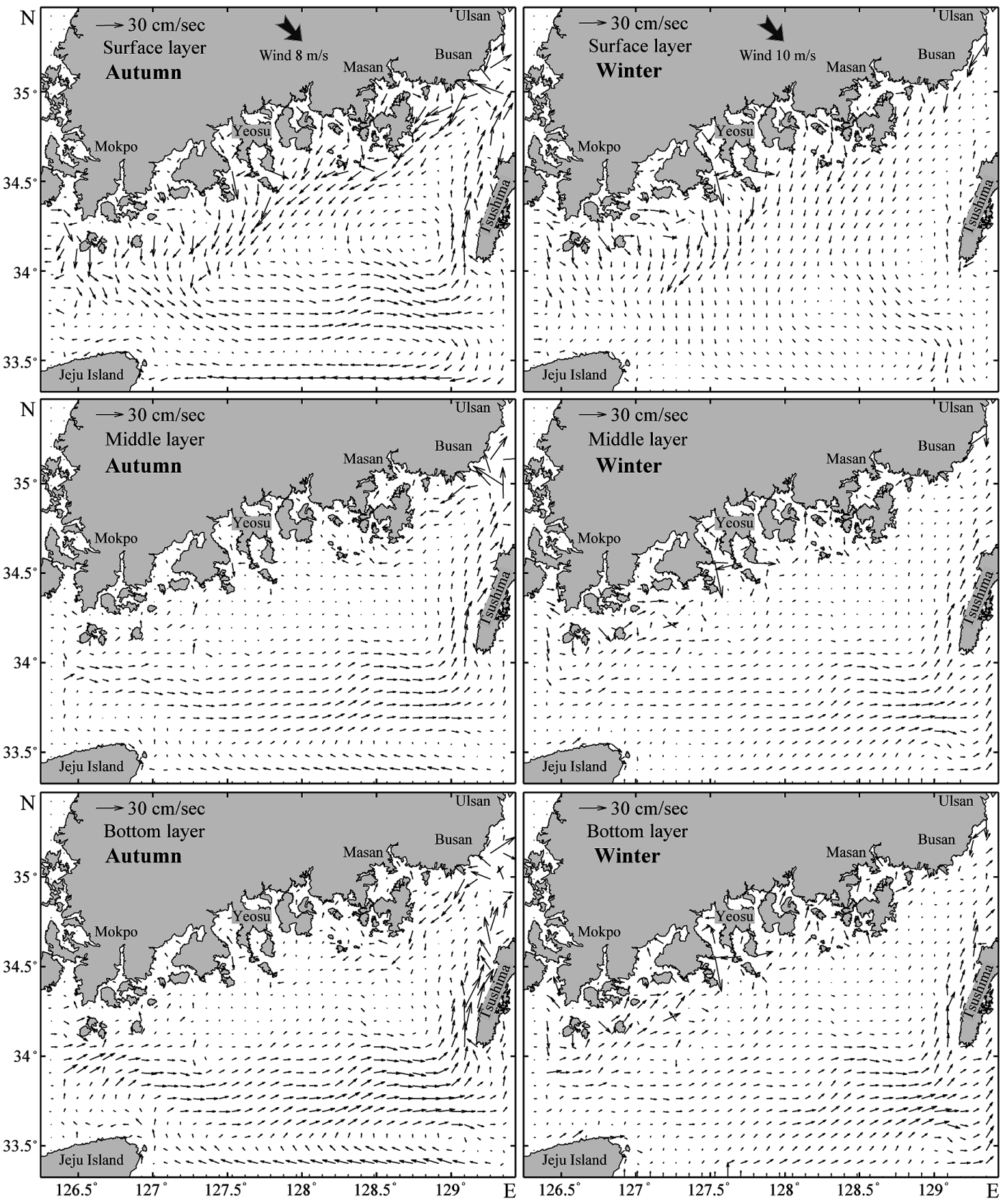

Fig. 4. wContinued.

the 30 days. However, in autumn and winter, they moved northward or northeastward of Bogildo-Cheongsando through the 30 days. In the summer, it shifted to the east of Cheongsando.

Therefore, seasonal movement of the northern group can be abstracted that they tend to drift westward, rather than eastward, in western regions of the South Sea of Korea when southeasterly wind prevails. In the meantime, the Jeju group tends to move northeastward, rather than stagnating near the initially released area. During the autumn and winter, larvae near the western area of the northern group and the Jeju group moved eastward after meeting in the front where coastal water and open water meet (Nishikawa et al., 1995; Bae and Kim, 2011). This can be speculated that they floated northeastward by residual flow until they are able to swim.

\section{Biomass Change of Anchovy Larvae (With Biological Activity)}

The growth of anchovy larvae largely depends on temperature and food availability in the study area (NFRDI, 2010a and b). Prior to simulating biomass change, the spatial distribution of zooplankton, the main food of anchovy larvae, was estimated using a low-tropic model for initial distribution. The initial value of biomass for one individual was assumed as " 1 ," without units. Therefore, the results indicate magnification of biomass compared to the initial value. Since time and spatial variations of biomass changes are extremely wide, every figure has a different index scale (Fig. 6).

In the spring, biomass began to increase from the 

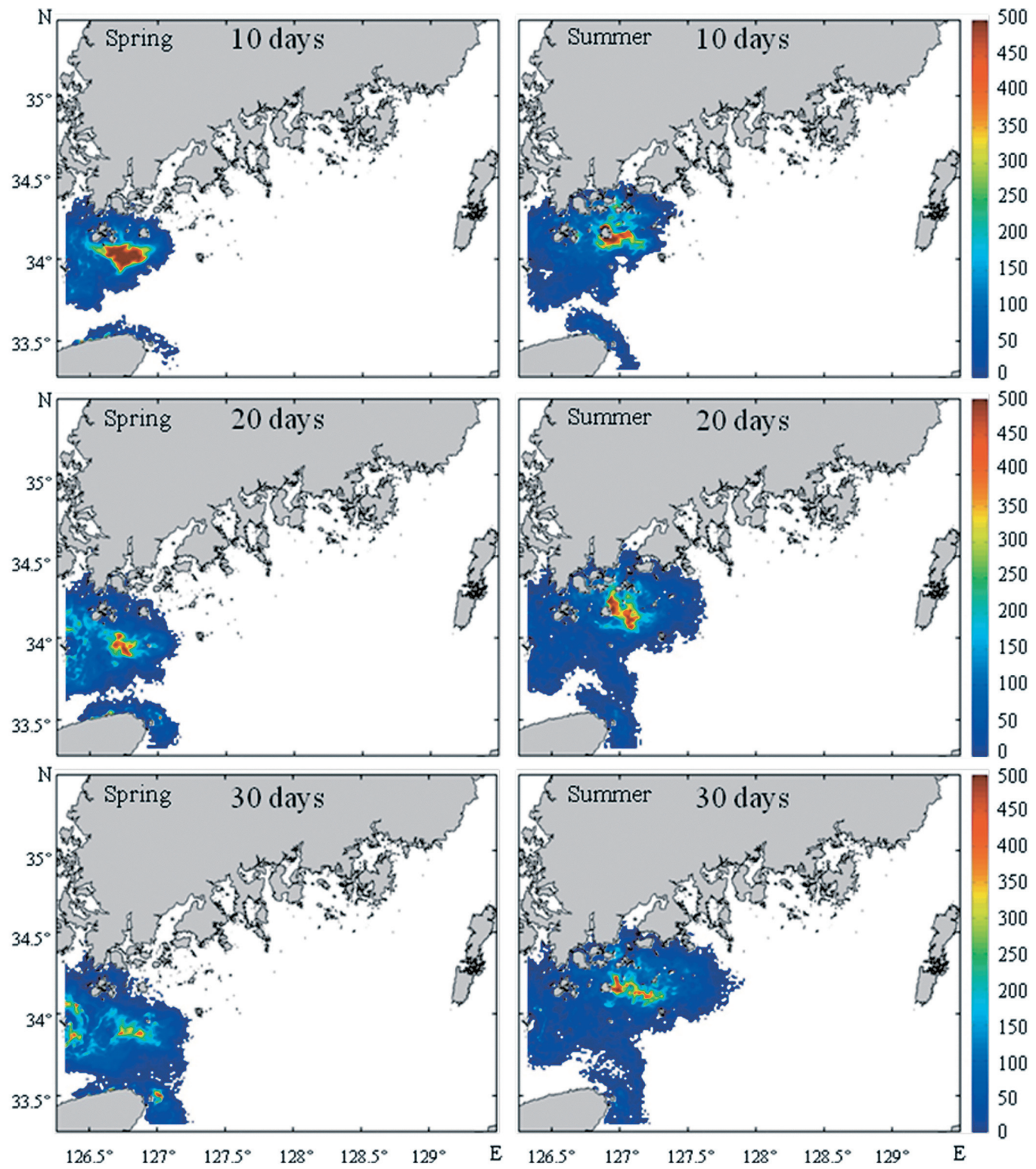

Fig. 5. Time and spatial variation of anchovy larval drift for four seasons (index: number of larvae).

adjacent Cheongsando, northeast of the northern group, while extending to the western boundary by western residual flows and southeasterly winds after the first 10 days. However, it is hard to recognize the increase in biomass in the Jeju group except a spot near the north coast. After 20 days, the high value began to expand broadly and some showed relatively high values even near the western boundary in the northern group. The Jeju group appeared to have much increased biomass, showing 15 times at the north coast. After 30 days, the value became higher than 25 times, covered by $62 \%$ by the northern group. The Jeju group showed the highest value of 35 times at the end of 30 days.

In the summer, the highest biomass over 12 times appeared to the east of the Cheongsando in the northern group after 10 days. Distinctively two higher values were separated by the relatively lower biomass in middle in the northern group. The Jeju group began to increase biomass near the northeast coast of Seongsan. After 20 days, biomass higher than 60 times covered 28\% and concentrated in the eastern area in the northern group. Some of the Jeju group increased by 5 times compared to the previous 10 days in the coast of Seongsan. After 30 days, biomass increased almost 3 times than at 20 days in both groups. Since rainfall was concentrated during the summer in the study area, the summer's productivity was higher than that of other seasons by the incoming nutrients from land.

In the autumn, higher biomass appeared near Goheung, showing to be about 6 times increased in the northern group after 10 days. Relatively high values covered near the coast compared to offshore regions. The Jeju group showed the highest biomass of 8 times near the coast of Seongsan after 10 days. After 20 days, the highest biomass increased 5 times in the northern group and 3 times in the Jeju group compared to that from the previous 10 days'. After 30 days, the highest value in the northern group reached 92 times, which is almost 3 

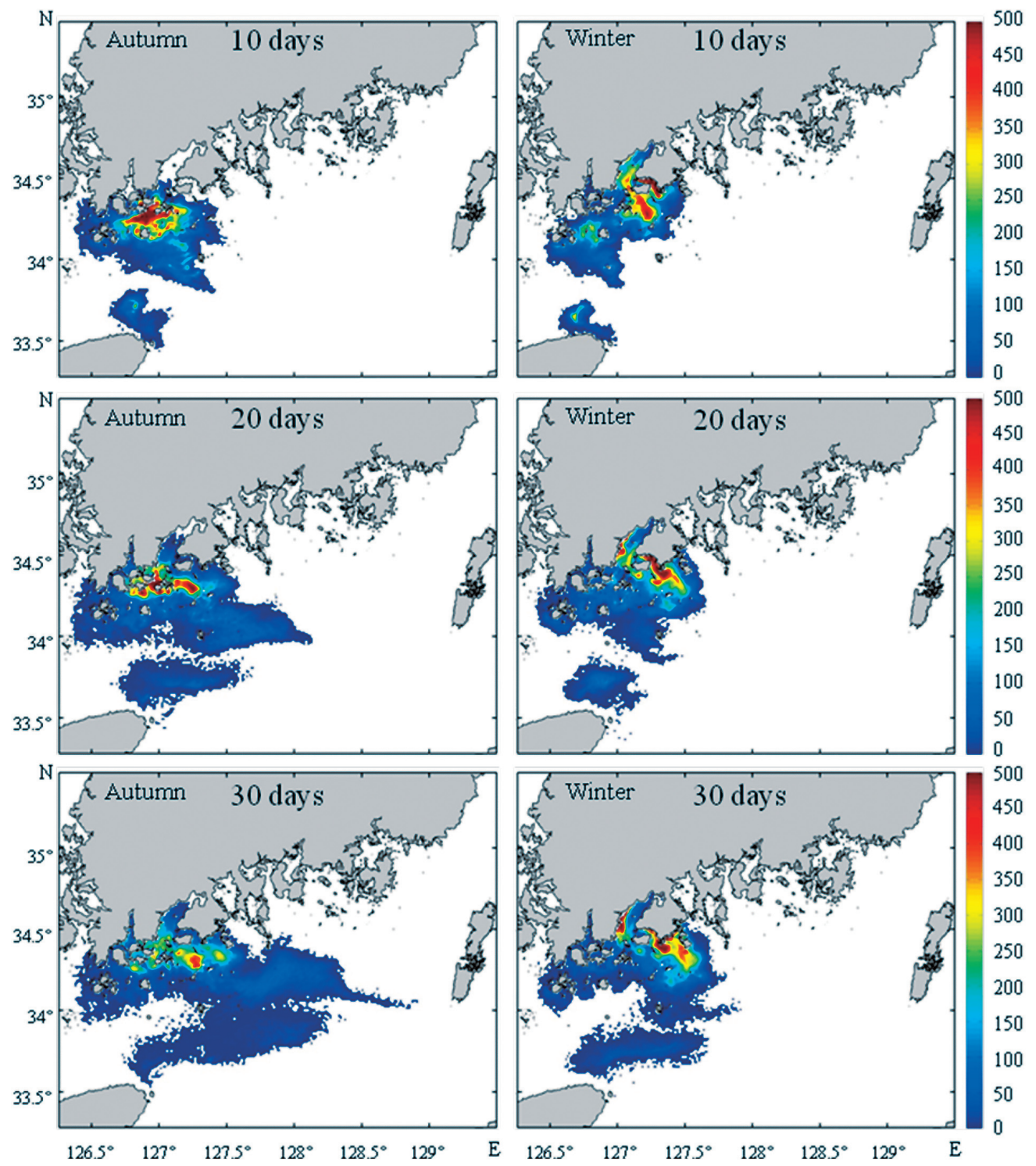

Fig. 5. Continued.

times higher, while the highest value the Jeju group increased by 2.5 times compared to that from the previous 10 days.

In the winter, as expected, biomass increase was the lowest through the 30 days compared to the other seasons due to low temperature and low nutrients concentration. Generally, the biomass increase in the Jeju group was faster than that of the northern group due to relatively high temperatures. Biomass increased around 2 3 times in both groups every 10 days.

In summary, summer had the highest biomass increase, affected by high temperature and high concentration of nutrients transported from land due to high rainfall during June-July (KMA, 2012). Further, due to the strong formation of the water front during summer between coastal waters and Tsushima Warm Currents in the South Sea of Korea, the productivity was higher than during the other two seasons. On the contrary, winter had the lowest biomass increase due to low temperature and low nutrients production.

\section{DISCUSSION}

In order to study the time and spatial movement of individuals and growth of anchovy larvae in the South Sea of Korea, the dispersion and biomass increase in individuals were examined by numerical simulation during the stage when larvae did not have free swimming ability in two cases - without biological activity and with biological activity. After calculating spatial centers of two cases, time varying trajectories of the two centers were analyzed for 5 day intervals for 30 days (Fig. 7).

Generally, both trajectories changed northeastward by the residual flow and nutrient concentration, except in the spring. In the spring, each of the two centers shifted within $18 \mathrm{~km}$ in diameter without distinct direction through the 30 days around the south of CheongsandoBogildo. Even after 30 days, the two centers departed only $6 \mathrm{~km}$. It can be deduced that residual flows and winds were weaker than during other seasons and that nutrients were concentrated in this area during the 

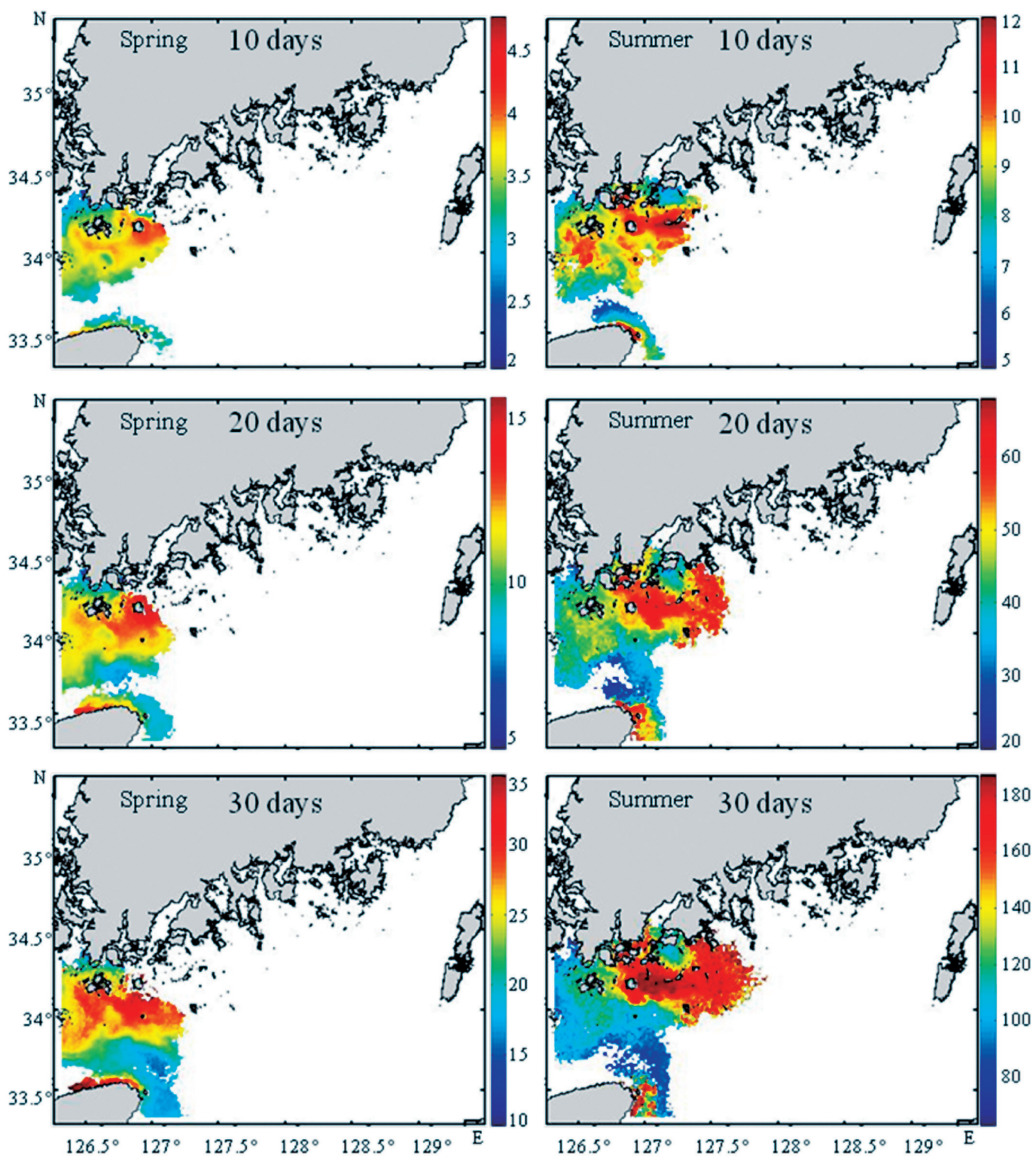

Fig. 6. Time and spatial variation of anchovy larval growth for four seasons (index: times of larval growth).

spring (NFRDI, 2004 2008). In the summer, the distance between two centers after 30 days was about $12 \mathrm{~km}$, which was twice as much as that of spring. The two centers began to separate after passing Cheongsando. Individuals were pushed inshore by residual flows and then were trapped until the 25th day of simulation. In the meantime, the center of biomass changed relatively quickly to the south of Bogildo, a nutrient-rich area. As mentioned earlier, the strong formation of water front between coastal water and Tsushima Warm Currents caused nutrients to concentrate during the summer in the South Sea of Korea. Previous studies showed that anchovy's main food, such as Copepod Nauplus (Funakoshi et al., 1983), was abundant near the southeast of Bogildo during the summer (Owen et al., 1989; Choo and Kim, 1998). The change in biomass center is interpreted to be a coupled effect by the formation of front and riverine influence during the summer. In the autumn, the distance between the two centers was almost $19 \mathrm{~km}$ after 30 days. Both centers moved near Cheongsando for the first 5 days, and then they began to separate until the end of the simulation period. The center of individuals was altered to inshore by residual flows, while the center of biomass was directly headed to the main fishing grounds, where nutrients were rich by the riverine influence (Fig. 2, inside the dotted line). In the winter, unlike during other seasons, the two centers separated in opposite directions after 10 days. The center of individuals was rapidly shifted inshore by the wind and residual flows. The center of biomass, however, was altered offshore, where the water temperature was higher than that of inshore.

Almost $60 \%$ of the total anchovy catch in Korea has been made offshore of Geojedo in the South Sea of Korea (Fig. 2, inside the dotted line; NFRDI, 2010b). Even though the seasonal difference in distribution and movement of anchovies depends on the state of the sea, generally, anchovies spend their adult life offshore of the 

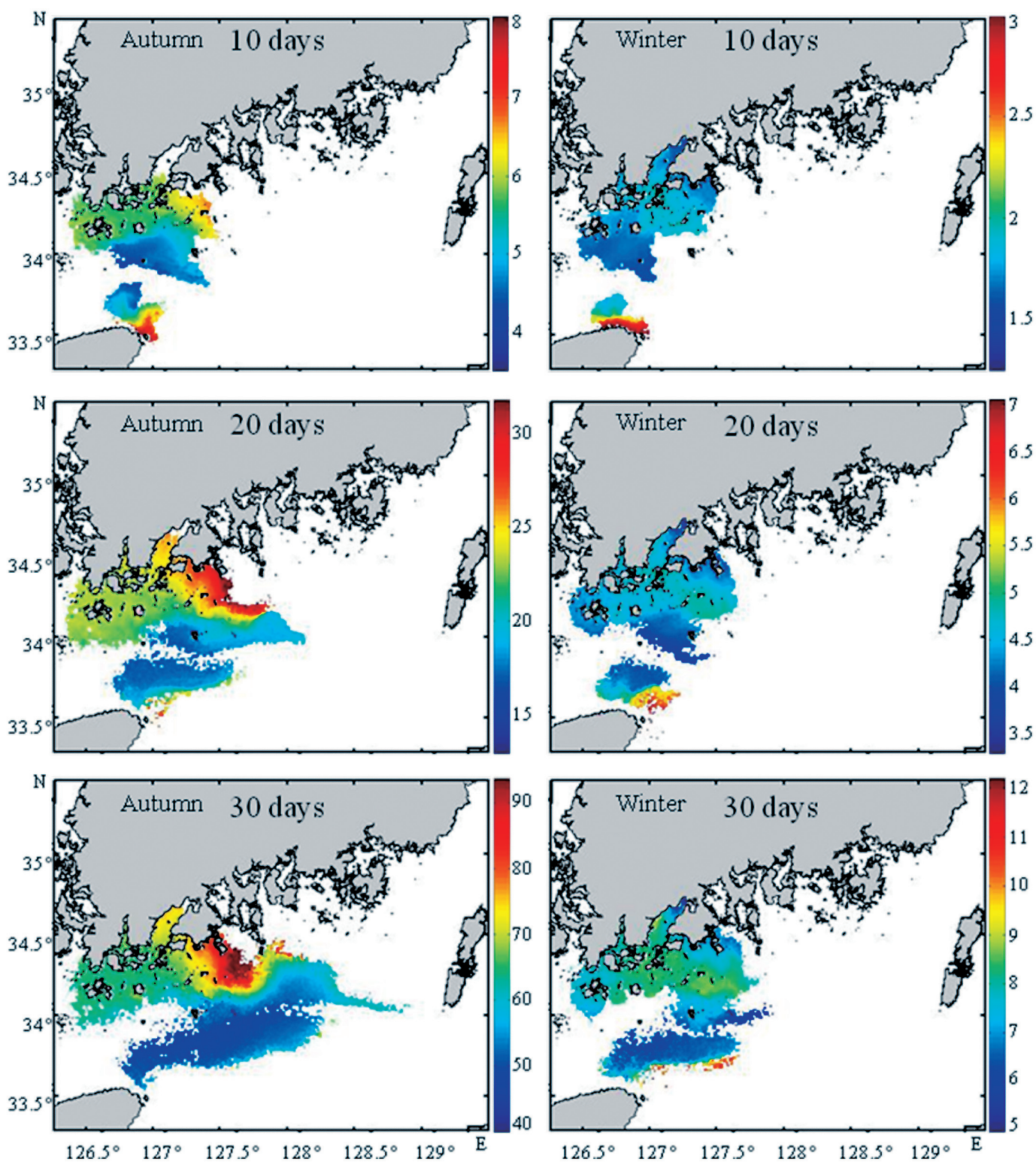

Fig. 6. Continued.

Namhaedo-Gejedo in August after forming vast schools during July-August. Thus, after spawning at the west of the South Sea of Korea, most larvae are moved offshore of Yeosu in July, and then enter the main fishing grounds after 30 days. In the meantime, some larvae from the spawning ground drift northward, reaching $37^{\circ} \mathrm{N}$ in latitude, to the main fishing ground, in August in the Yellow Sea (Kim, 1983; NFRDI, 1998b; NFRDI 2010a). In the results from the model, some larvae traveled westward and finally hit the western boundary during the spring and summer (Fig. 5). Presumably, westward anchovies joined main fishing grounds in the Yellow Sea a month later. If the study area is expanded to the west and the north, the northward drift of larvae may be reproduced.

Likewise, time and spatial difference between individual distribution and biomass increase is closely related to the distribution of nutrients, as well as physical environment (Takasuka and Aoki, 2006). Relatively higher biomass was concentrated near the front during the summer after 20 days. This result was correlates well with findings from previous studies (Fig. 6) (Gong, 1971; Huh, 1974; Noh, 1990; Bae and Kim, 2011). It has been known that the productivity and diversity of species are high near the front (Bowman and Easias, 1977; Ishizaki et al., 1984). Therefore, the formation and location of front play very important roles in anchovy migration in the South Sea of Korea (Chang et al., 1980). Usually, the distribution of anchovy eggs is limited to coastal areas when a strong front forms in the summer (Kim, 1983) while anchovy larvae inhabit near both sides of the front (Kim, 1983; Choo and Kim, 1998). The simulation results showed that winter was the lowest biomass increase of the four seasons. Even after 30 days, the increase was only 8-9 times except in the southern area of the Jeju group. Thus, the spawning ground moves to the south of Jeju Do and the west of Kyushu in East China Sea during the winter (NFRDI, 2010b).

For the purpose of validation, indirect comparison 


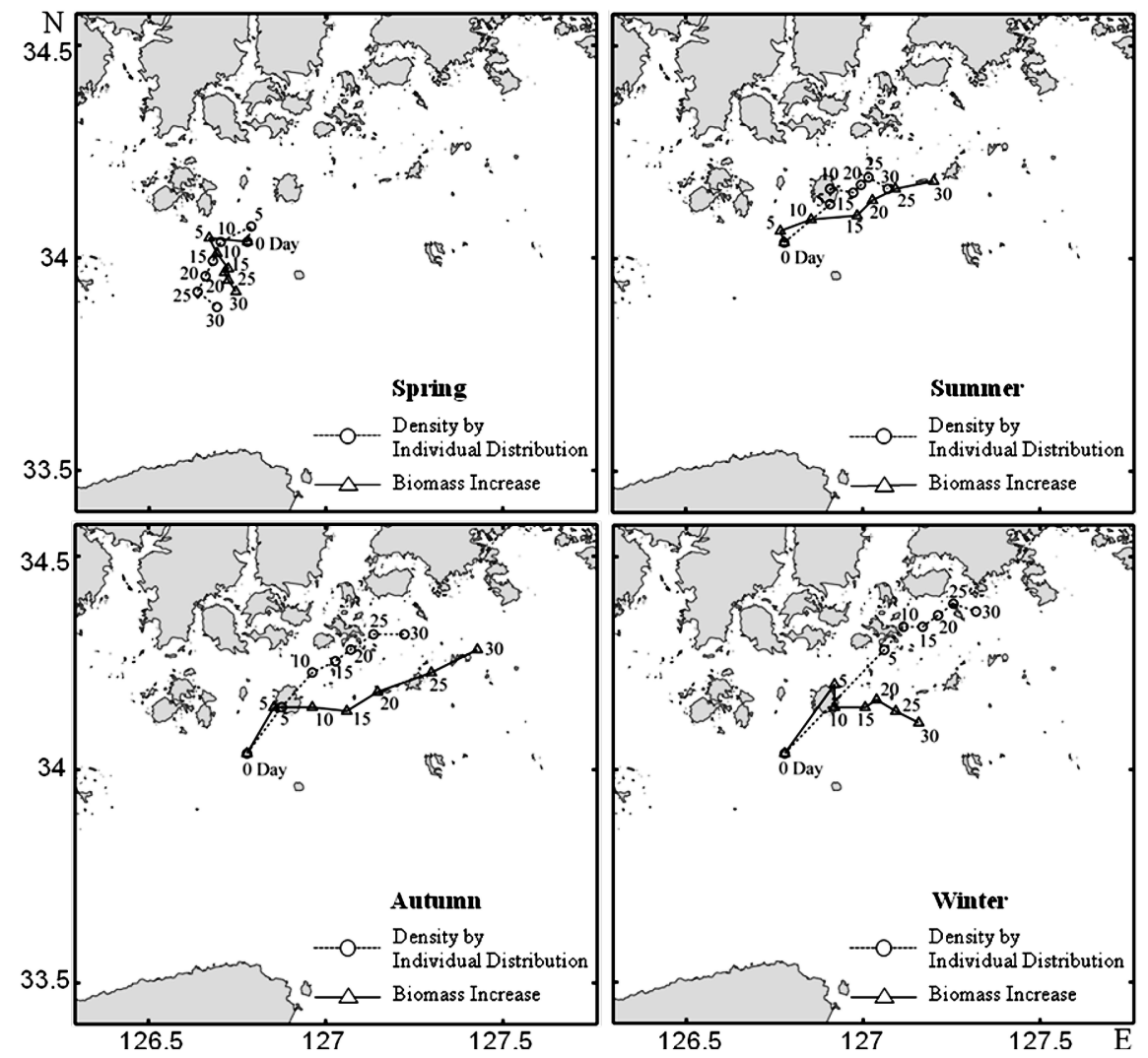

Fig. 7. Comparison between two centers, individual distribution and biomass increase of anchovy larvae for 5 days interval (domain: dotted square area in Fig. 1).

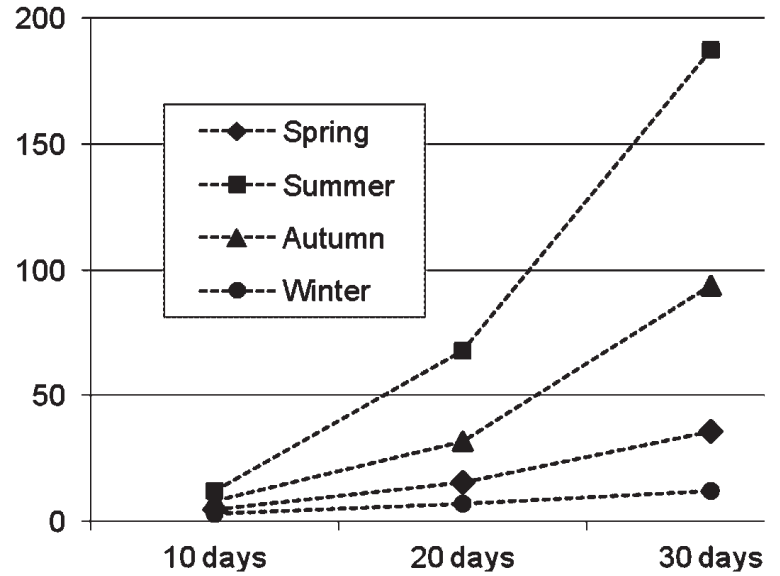

Fig. 8. Anchovy larval growth change in multiplication against initial value " 1 ".

was made between the growth rate of larvae and biomass change obtained from the model. Due to the shortage of measurement of weight data from hatching to one month of growth, we simply applied the equation, Weight $=0.004$ Length $^{3.2748}$ (Cha, 1990), optimized for Korean waters. An assumption was made that even early stage anchovy growth follows the above equation. Larvae length, on average, reaches about $3.7 \mathrm{~mm}$ after hatching and $19.5 \mathrm{~mm}$ after 30 days (Cha, 1990). Therefore, biomass is estimated to be $0.29 \mathrm{mg}$ and $67.09 \mathrm{mg}$ after hatching and 30 days, respectively, by allowing a 231 factor increase from hatching to 30 days. Due to the wide range of the length after hatching, factor also varies widely. Thus, it is considered that simulation results fall into actual values, in which maximum biomass increase was 187 times after 30 days (Fig. 8).

As a preliminary experiment, the results may be somewhat distant from the actual value since larvae data from one season was used as an initial distribution for all seasons. However, our results showed at least that the distribution and growth of larvae vary greatly depending on physical and biological conditions. If input data are strengthened, the movement from the spawning to growing ground and biomass change will be successfully produced.

\section{REFERENCES}

Bae, S. W. and D. S. Kim 2011 Seasonal variation of coastal front by numerical simulation in the Southern Sea of Korea. J. of Environmental Sci., 20: 1141-1149

Blumberg A. F. and G. L. Mellor 1987 A description of a threedimensional coastal ocean circulation model. In : Three dimensional Coastal Models (N. S. heaps, ed.), American Geophysical Union, Washington, D.C., 1-16

Bowman. M. J. and W. E. Esaias 1977 Oceanic fronts in coastal processes. Springer-Verlag, p. 114

Cha, S. S. 1990 Age and Growth of Anchovy (Engraulis japonica) Juvenile in the Coastal Waters of Chonnam, Korea. Bull. Korean Fish. Soc., 23: 385-393

Chang, K. I., K. Kim, S. W. Lee and T. B. Shim 1995 Hydrography and sub-tidal current in the Cheju Strait in Spring. J. Oceanol. Soc. Korea, 30: 203-215 
Chang, S. D., S. Y. Hong, C. K. Park, P. Chin, B. G. Lee, T. Y. Lee, Y. J. Kang and Y. Gong 1980 Studies on the migration on anchovy Engraulis japonica in Korean waters. Publ. Inst. Mar. Sci. N.F.U.B., 12: $1-38$

Cho, B. C. and F. Azam 1990 Biogeochemical significance of bacterial biomass in the ocean's euphotic zone. Mar. Ecol. Prog. Ser., 63: 2253-259

Cho, Y. K. and K. Kim 1995 Characteristics and origin of the Cold Water in the South Sea of Korea in Summer. J. Oceanol. Soc. Korea, 29: 414-421

Choo, H. S. and D. S. Kim 1998 The Effect of Variation in the Tsushima Warm Currents on the Egg and Larvae Transport of Anchovy in the Southern Sea of Korea. Bull. Korean Fish. Soc., 31: 226-244

Eppley, R. W., W. G. Harrison, S. W. Chisholm and E. Stewart 1977 Particulate organic matter in surface waters off Southern California and its relationship to phytoplankton. J. Mar. Res., 35: $671-696$

Ezer T., H. Arango and A. F. Shchepetkin 2002 Developments in terrain-following ocean models: intercomparisons of numerical aspects. Ocean Modelling, 4: 249-267

Funakoshi, S., F. Muranaka and T. Ikeda 1983 Food and survival of the early Postlarvae of the Japanese Anchovy, Engraulis japonica (Houttuyn)-1. Bull. Japan. Soc. Fish. Oceanogr., 44: $76-86$

Gaylord B. and S. D. Gaines 2000 Temperature or transport? range limits in marine species mediated solely by flow. Am. Nat., 155: 769-789

Gong, Y. 1971 A study on the south Korean coastal front. $J$. Oceanol. Soc. Korea, 6: 25-36

Heath, M. 1989 Transport of Laval Hering (Clupea harengus the Scott is L.) by Coastal Current. Rapp. P. V.R n. cons. int. Mer., 191: 85-89

Huh, O. K. 1974 Coastal oceanographic use of the defense meteorological satellite program (DMSP). Naval Oceanographic Office Technical Rept., 241: 1-12

Ishizaki, J. and M. Takahashi 1984 Chlorophyll production and its accumulation in the frontal region of the Kuroshio Branch off Izu-Shimoda. J. Oceanogr. Soc. Japan, 21: 148-155

Ivlev, V. S. 1966 The biological productivity of waters. Journal of the Fisheries Research Board of Canada, 23: 1727-1759

Kim, B. G. and Y. B. Ko 2003 The Present Condition of Fishes in Jeju-do coast. Proceedings of the Korean. J. Ichthyol, Conference, 23-27

Kim, J. Y. 1983 Distribution of Anchovy Eggs and Larvae off the Western and Southern Coasts of Korea. Bull. Korean Fish. Soc., 16: 401-409

Kim, J. Y. and Y. M. Choi 1988 Vertical Distribution of Anchovy, Engraulis japonica Eggs and Larvae. J. Fish. Sci. Tech., 2: $139-144$

Kim, J. Y. and Y. J. Kang 1992 Spawning Ecology of Anchovy, Engraulis japonica, in the Southern Waters of Korea. Bull. Korean Fish. Soc., 25: 331-340

Kim, J. Y. and N. C. H. Lo 2001 Temporal variation of seasonality of egg production and the spawning biomass of Pacific anchovy, Engraulis japonicus, in the southern waters of Korea in 1983-1994. Fish. Oceanogr., 10: 297-310

Kim, K., K. R. Kim, T. S. Rho and H. K. Rho, R. Limeburner and R. C. Beardsley 1991a Identification of water masses in the Yellow Sea and the East China Sea by cluster analysis, Oceanography of Asian marginal seas, by K. Takno. Elsevier, 253-267

Kim, K., H. K. Rho and S. H. Lee 1991b Water masses and circulation around Cheju-Do in summer. J. Oceanol. Soc. Korea, 26: $262-277$

KMA 2012 The Climate Atlas of Korea, Korea Meteorological Administration. Publish No. 11-1360000-00830-13, p. 174

KORDI 1996 Harmonic constants of tide around the Korea Peninsula (1). Korea Ocean Research Development Institute, p. 541

Lee. C. L. 2004 Review of the Fish-fauna of the West Sea of Korea.
Korean Journal of Ichthgology, 16: 60-74

Lee, I. W. and D. S. Kim 1998 Environmental Condition of Sea Areas for Anchovy Lift Net in Kamak Bay. Bull. Korean Soc. Fish. Tech., 34: 67-73

Lie, H. J. and C. H. Cho 1997 Surface Current Fields in the Eastern East China Sea. J. Oceanol. Soc. Korea, 32: 1-7

Lo, N. C. H., J. R. Hunter and R. P. Hewitt 1989 Precision and bias of estimates of larval mortality. Fishery Bull., 87: 399-416

Luyten, P. J., J. E. Jones, R. Proctor, A. Tabor, P. Tett and K. WildAllen 1999 CORHERENS-a couple HydrodynamicalEcological Model for Regional and Shelf Seas: User Documentation. MUMM Report. Management Unit of the Mathematical Models of the North Sea, p. 911

Nakata, H. 1991 Coastal processes related to the transport, survival and recruitment of fish larval. J. Oceanogr. Soc. Japan 28: $195-220$

NFRDI 1998b Korean Coastal and Offshore Fishery Census National Fisheries Research \& Development Institute, 96-102

NFRDI 2004 Studies on the Transportation Mechanism of the Eggs and Larvae of Anchovy in the Surrounding Sea of Jeju Island. National Fisheries Research \& Development Institute, p. 156.

NFRDI 2004-2008 Annual Report of Korean Coastal Environment Monitoring 2003-2007. National Fisheries Research \& Development Institute, Vol. 9-13

NFRDI 2010a Korean Coastal and Offshore Fishery Census. National Fisheries Research \& Development Institute, 110-117

NFRDI 2010b Ecology and Fishing Ground of Fisheries Resources in Korean Waters. National Fisheries Research \& Development Institute, 252-254

Nishikawa, J., A. Tsuda, T. Ishigaki and M. Terazaki 1995 Distribution of euphausiids in the Kuroshio front and warm water tongue with special reference to the surface aggregation of Euphausia pacifica. J. Plankton Res., 17: 611-629

Noh, H. G. 1990 Studies on the Tsushima Current in the South Sea of Korea. KOSEF 870616, 94-103

Owen, R. W., N. C. H. Lo, J. L. Bulter, G. H. Theilacker, A. Alvarino, J. R. Hunter and Y. Watanabe 1989 Spawning and survival patterns of larval northern anchovy, Engraulis mordax, in contrasting environment-A site-intensive study. Fish Bull. 87: $673-688$

Park, H. H. and G. D. Yoon 1996 Analysis and Prediction of Anchovy Fisheries in Korea ARIMA Model and Spectrum Analysis. Bull. Korean Fish. Soc., 29: 143-149

Park, K. J. and S. S. Cha 1995 Food Organisms of Postlarvae of Japanese Anchovy (Engraulis japonica) in Kwangyang Bay, Korea. Bull. Korean Fish. Soc., 28: 247-252

Petipa, T. S. 1966 Relationship between growth, energy metabolism, and ration A. clause. Physiology of Marine Animals, Akad. Nauk., USSR, Oceanographical Commision, 82-91

Seo, Y. J. and D. S. Kim 1999 Distribution of Anchovy School catched by the lift Net and Environmental Factors in the Kamak Bay 1. Relation between distribution of the Anchovy School and Temperature and salinity. Bull. Korean Soc Fish. Tech., 35: 267-276

Siegel, D. A., B. P. Kinlan, B. Graylord and S. D. Gaines 2003 Lagrangian descriptions of marine larval dispersion. Marine Ecoly Progress Series, 260(C): 83-96

Suk, M. S., G. H. Hong, C. S. Chung, K. I. Chang and D. J. Kang 1996 Distribution and Transport of Suspended Particulate Matter, Dissolved Oxygen and Major Inorganic Nutrients in the Cheju Strait. J. Oceanol. Soc. Korea, 31: 55-63

Takasuka, A. and I. Aoki 2006 Environmental determinants of growth rates for larval Japanese anchovy Engraulis japonicus in different waters. Fish. Oceanogr. 15: 139-149

Teague, W. J., G. A. Jacobs, H. T. Perkins, J. W. Book, K. I. Chang and M. S. Suk 2002 Low-Frequency Current Observations in the Korea Strait. J. Phy. Ocea., 32: 1621-1641

Whang, C. and W. S. Kim 1977 Set Net Catches of Anchovy, Engraulis japonica (Houttuyn) as Related to Environment. J. Oceanol. Soc. Korea, 12: 1-16 